\title{
Subsistema normativo de Ciência, Tecnologia e Inovação
}

\author{
Gustavo Alberto Silva Coutinho ${ }^{1}$; André Vasconcelos da Silva 2
}

\section{Resumo}

O presente artigo tem como objetivo apresentar uma análise do subsistema normativo de Ciência, Tecnologia e Inovação nas leis brasileiras. Para tanto, foram utilizados como referências artigos científicos que tratam das leis que disciplinam as atividades de Ciência, Tecnologia e Inovação, partindo da Constituição Federal e passando pela Lei de Inovação, Lei do Bem e o novo Código Brasileiro de Inovação. Também foi feita uma análise dos textos das próprias leis mencionados, que constituem um verdadeiro subsistema normativo de Ciência, Tecnologia e Inovação.

Palavras-chave: Ciência, Tecnologia e Inovação; subsistema normativo; leis

\section{INTRODUÇÃO}

O presente trabalho apresenta uma análise do subsistema normativo de Ciência, Tecnologia e Inovação na legislação brasileira, com suporte em artigos científicos que trataram das normas apresentadas.

Portanto, parte-se da análise da Constituição Federal, apresentando o título VIII, artigos 218 e 219, que tratam do chamado sistema nacional de ciência e tecnologia.

Em seguida, é feita a análise da Lei de Inovação Tecnológica, de 2004, importante marco legal para criação de um ambiente favorável à produção de inovações tecnológicas, e da Lei do Bem, que trata de incentivos fiscais para empresas que investirem em pesquisa de inovação tecnológica.

Por fim, é apresentada uma análise do novo Código de Ciência, Tecnologia e Inovação, que entrou em vigor em janeiro de 2016 e regulamentou a Emenda Constitucional 85 , de 2015, e promoveu significativa modificação do texto original não só da Lei de Inovação Tecnológica como de outras normas relacionadas à Ciência, Tecnologia e Inovação.

\section{DESENVOLVIMENTO}

\subsection{A Constituição Federal}

O marco jurídico de ciência, tecnologia e inovação no Brasil tem como base ou matriz configuradora a Constituição Federal (WILLIG, 2014), na qual se enfatiza o papel do Governo como promotor de ciência e tecnologia (MENEZES, 2015). A temática de ciência, tecnologia e inovação foi inserida no texto da atual Constituição Federal, no título VIII, artigos 218 e 219, os quais fixam uma arquitetura básica da organização jurídica do sistema nacional de ciência e tecnologia, com participação de entidades públicas e privadas, fomento e atividades desempenhadas, com atuação 
Empresarial no Centro de Ensino Superior de Catalão - CESUC; pesquisa financiada pela FAPEG.

2 Doutor em Ciências do Comportamento; Coordenador do Laboratório de Análise Organizacional e Consumo da Universidade Federal de Goiás.

do Estado federativo (União, Estados e Municípios) e sua relação em conjunto com

empresas e sociedade organizada, a ser detalhada em legislação superveniente (VERONESE, 2014).

Recentemente, em fevereiro de 2015, os artigos 218 e 219 sofreram alteração de suas redações pela Emenda Constitucional 85, a qual acrescentou, ainda, alguns parágrafos a eles e os novos artigos 219-A e 219-B a tal capítulo da Constituição. Para Veronese (2014), o artigo 218 trata da produção científica e tecnológica num contexto de sua imersão social e distingue o desenvolvimento científico (pesquisa básica) e a pesquisa e capacitação tecnológica (pesquisa aplicada). Segundo Willig (2014), a pesquisa científica é direcionada a toda a humanidade e para o progresso científico, enquanto a pesquisa tecnológica constitui instrumento de desenvolvimento social que atende interesses da população na medida em que resolva prioritariamente problemas brasileiros, voltando-se para o desenvolvimento econômico e regional.

Veronese (2014) destaca, ainda, que tais dispositivos constitucionais indicam duas direções para atuação estatal: a promoção, que abrange a necessidade de existir envolvimento do Estado no que diz respeito à ocorrência de dotações orçamentárias para o fomento desse tipo de atividade, por meio da criação de e manutenção de entidades estatais (institutos de pesquisa, universidades), auxílio à existência de entes quase-estatais (organizações sociais) e fomento de atividades de pesquisa científica e tecnológica em entes públicos e privados (faculdades, centros universitários, universidades, empresas com viés tecnológico); e o incentivo, que abrange a criação de mecanismos institucionais para facilitar tais finalidades, na forma de incentivos fiscais e arranjos institucionais voltados ao desenvolvimento científico e tecnológico.

Willig (2014) destaca que o texto constitucional apresenta clara distinção dos propósitos do desenvolvimento científico e dos da pesquisa e capacitação tecnológica, pois esse desenvolvimento tem como base um dos objetivos fundamentais da Constituição de 1988, qual seja, garantir o desenvolvimento nacional e a promoção da ciência e tecnologia é condição de concretização de tal objetivo.

Diante disso, que novidades vem trazer a Emenda Constitucional 85 para as atividades de ciência tecnologia e inovação? Denis Borges Barbosa (2015) já tratou do tema e, para ele, a maior parte das mudanças trazidas pela Emenda aos arts. 218 e 219 da Constituição não terá grande efeito prático. Para ele, a introdução do termo "inovação" no texto constitucional mostra mais sensibilidade a modismos de terminologia do que atenção às necessidades da política pública, uma vez que, ao se acrescentar o termo "inovação" aos já existentes "ciência" e "tecnologia", entender-seia que "inovação" não é "ciência", nem "tecnologia" e nem resultado delas, o que levaria à conclusão que a inovação não tecnológica (de marketing, de publicidade, de métodos de negócio, por exemplo) ganhou status constitucional.

Barbosa (2015) resume as alterações advindas da Emenda Constitucional 85 da seguinte maneira:

a) Primeiro, a explicitação de que ciência e tecnologia são de competência legislativa concorrente de todos os poderes de todos os entes federativos, o que só evidencia o que já era óbvio, pois o texto original da Constituição já previa que a promoção de ciência e tecnologia já estava no âmbito dos deveres constitucionais de todos esses entes. De fato, Veronese (2014) já afirmava que naquelas disposições constitucionais o Estado deveria ser compreendido em sentido amplo, reunindo a União e demais unidades federativas, de forma que não existissem obstáculos para haver institucionalização de sistemas estaduais ou municipais de apoio à formação de 
recursos humanos à ciência e tecnologia, por exemplo, consubstanciada nas Fundações de Amparo à Pesquisa - FAP's - que existem em quase todas as unidades federativas. 
b) A alteração do texto do art. 167 da Constituição pode ter alguma importância para o orçamento das atividades de ciência, tecnologia e inovação, ao passar a permitir, sem prévia autorização legislativa e por simples ato do Executivo, a transposição, remanejamento e transferência de recursos orçamentários no âmbito dessas atividades, com objetivo de viabilizar projetos restritos a elas.

c) O art. 200 da Constituição, que trata do sistema de saúde, também foi alterado para incluir o termo "inovação" ao já existente desenvolvimento científico e tecnológico.

d) $\mathrm{O}$ art. 213 da Constituição, que trata do financiamento público de instituições de ensino, teve alteração de redação de seu parágrafo segundo, aumentando o rol de atividades de universidades e Instituições de Ciência e Tecnologia - ICT's - privadas que podem ser apoiadas pelo Estado, além de acrescer também como beneficiárias as instituições de educação profissional e tecnológica, acrescentando às atividades de pesquisa e extensão as de estímulo e fomento à inovação.

e) No parágrafo terceiro do art. 218, a Emenda acrescentou, entre as atividades de recursos humanos a serem estimuladas, 0 apoio às atividades de extensão tecnológica.

f) O parágrafo sexto do art. 218 da Constituição passa a determinar que o Estado estimule a articulação entre entes públicos e privados para fins de ciência, tecnologia e inovação.

g) O parágrafo sétimo do art. 218 passa a prever a atuação de ICT's no exterior.

h) $\mathrm{O}$ art. 219 ganha um parágrafo único para acrescer à missão estatal de ciência tecnologia e inovação a as atividades de parques e polos tecnológicos e demais ambientes promotores de inovação, atuação de inventores independentes e criação, absorção, difusão e transferência de tecnologia.

i) Acrescenta-se um artigo 219-A para dar status constitucional à promoção de cooperação de entes federativos com órgãos e entidades públicas ou privadas, para execução de projetos de pesquisa, desenvolvimento científico, tecnológico e de inovação, o que já previa o art. 19 da Lei de Inovação (Lei 10.973, de 2 de dezembro de 2004), a qual será detalhada mais adiante.

j) Também se acrescenta um artigo 219-B para instituir, em nível constitucional, o Sistema Nacional de Ciência, Tecnologia e Inovação - SNCTI, com a previsão de uma futura lei nacional para regular o sistema.

Para Barbosa (2015), então, basicamente a Constituição dizia e continua dizendo, após a Emenda 85, que é encargo do Estado, por meio de todos os entes federativos, a promoção e o incentivo do desenvolvimento científico à pesquisa e à capacitação tecnológica, distinguindo claramente os propósitos do desenvolvimento científico, de um lado, e os de pesquisa e capacitação tecnológica, de outro, no contexto do direito constitucional ao desenvolvimento, princípio básico que impõe à República o objetivo de garantir o desenvolvimento nacional. Esse direito ao desenvolvimento, já alertava anteriormente Veronese (2014), está contextualmente ligado ao tema de ciência e tecnologia na Constituição Federal, como parte da ordem social prevista no art. 193, embora em um segundo momento também seja relacionado com a noção de mercado em geral.

Veronese (2014) já destacava que pode ser estabelecido eixo de conexão entre o objetivo republicano de promoção do desenvolvimento e o art. 219, uma vez que a Constituição traçou, em relação à ciência e tecnologia, papel central para garantia da emancipação nacional.

\subsection{A Lei de Inovação Tecnológica}


Matias-Pereira e Kuglianskas (2005) afirmam que a produção científica do Brasil é de responsabilidade, em parcela significativa, das universidades públicas, o que torna o país produtor de ciência de fronteira, mas que não consegue interagir em nível adequado com o setor produtivo, o que implica em baixa incorporação de tecnologia de ponta diretamente nos produtos, tornando-os pouco competitivos.

Os autores continuam afirmando que a Constituição Federal definiu em linhas gerais o papel do Estado brasileiro nas diversas atividades de articulação, promoção e incentivo de ciência e tecnologia, ainda se faz necessário construir um arcabouço legal que contribua para uma maior integração entre desenvolvimento científico e tecnológico e a produção de inovação e, nesse contexto, ingressou em nosso ordenamento jurídico a Lei de Inovação Tecnológica (Lei Federal no 10.973, de 2 de dezembro de 2004), a qual tem como objetivo criar um ambiente propício para aumentar o envolvimento das empresas no desenvolvimento de projetos inovadores que levem a gerar novos produtos e processos, buscando-se uma elevação do nível de parcerias entre empresas, universidades e institutos científicos e tecnológicos para que ganhem força e estimulem o processo de inovação (MATIAS-PEREIRA e KUGLIANSKAS, 2005).

Para os mesmos autores, a Lei de Inovação Tecnológica está orientada para criar um ambiente de inovação propício a parcerias estratégicas entre universidades, institutos tecnológicos e empresas, estimular a participação de instituições de ciência e tecnologia no processo de inovação, incentivar a produção de inovação pelas empresas, permitir a incubação de empresas no espaço público e possibilitar o compartilhamento de infraestrutura, equipamentos e recursos humanos, públicos e privados, para o desenvolvimento tecnológico e a geração de processos e produtos inovadores, além de definir regras para que o pesquisador público possa desenvolver pesquisas aplicadas e incrementos tecnológicos, permitir o aporte de recursos orçamentários públicos diretamente às empresas em projetos de inovação. $\mathrm{Na}$ época, os autores alertavam que a intenção do governo federal era alterar o quadro então existente em que $73 \%$ dos cientistas atuavam em instituições públicas e apenas $11 \%$ em instituições privadas (MATIAS-PEREIRA e KUGLIANSKAS, 2005).

Mas, já naquela época, Matias-Pereira e Kuglianskas (2005) destacavam que, embora a Lei de Inovação tenha surgido como mais um instrumento para criar uma cultura de inovação no país, sua aprovação não era suficiente para mudar a realidade de produção de ciência, tecnologia e inovação, pois seria preciso um maior envolvimento dos atores envolvidos nesse contexto. Além disso, criticavam a lei por considerar que ela muito rígida na gestão de recursos humanos, financeiros e materiais das instituições de pesquisa. Na área de gestão da inovação, criticavam-na por considerarem que ela se restringia a estabelecer regimes de comercialização das inovações geradas nas instituições científicas e tecnológicas. Por fim, afirmavam tratar-se de uma lei muito incipiente, na época, e que precisaria de regulamentação por diploma legal significativamente extenso.

Denis Borges Barbosa (2007) também tratou da Lei de Inovação e indica que, entre as soluções propostas por ela, há também a previsão de várias formas de socialização dos riscos e custos da inovação, alternativa ou cumulativamente com a proteção por direitos exclusivos, o que leva à conclusão que a Lei de Inovação opta pela apropriação privada dos resultados através da construção jurídica de uma exclusividade artificial (patentes, direitos autorais). Segundo o mesmo autor, a estratégia da lei é associar estímulos diretos à inovação pelo setor privado, por meio de concessão direta de recursos financeiros, infraestrutura e pessoal, como transferência de recursos do contribuinte, uso estratégico da capacidade inovadora 
das instituições em aliança com o setor privado, uso do poder de compra do Estado, essencialmente através das compras de tecnologia e, através da Lei do Bem (Lei 11.196/2005, que será tratada adiante), a renúncia fiscal.

Barbosa (2007) divide a Lei de Inovação em cinco grandes grupos de normas, quais sejam:

a) Constituição de ambiente propício às parcerias estratégicas entre as universidades, institutos tecnológicos e empresas, propiciando a cooperação entre os atores do processo de inovação, reduzindo as barreiras institucionais entre setor privado e ICT's, constituindo, assim, articulações horizontais entre os dois lados (academia e empresas).

b) Estímulo à participação de instituições de ciência e tecnologia no processo de inovação, propósito do corpo principal das normas da Lei de Inovação, facultando às ICT's celebrar contratos de transferência de tecnologia e de licenciamento de patentes de sua propriedade e prestar serviços de consultoria especializada em atividades desenvolvidas pelo setor produtivo, conforme se verifica no conteúdo dos artigos 6은, $7^{\circ}$ e $8^{\circ}$.

c) Incentivo ao pesquisador-criador, de forma a estimular a natureza especial do trabalho criativo, possibilitando aos pesquisadores vinculados a ICT's beneficiar-se do resultado financeiro do serviço técnico especializado prestado a instituições públicas ou privadas (art. $8^{\circ}$ ), além de sua remuneração normal.

d) Incentivo à inovação na empresa, por meio de concessão, por parte da União, ICT's e agências de fomento, de recursos financeiros, humanos, materiais ou de infraestrutura, para atender às empresas nacionais envolvidas em atividades de pesquisa e desenvolvimento, e tais recursos financeiros serão consubstanciados em subvenção econômica, financiamento ou participação societária.

e) Apropriação de tecnologias, em cumprimento ao princípio constitucional de que as tecnologias devem ser primordialmente apropriadas em favor do setor produtivo nacional, impondo que a produção de conhecimento pelas ICT's fique sujeita a uma regra primordial de apropriação e não de lançamento em domínio público.

A preocupação do governo ao editar a Lei de Inovação era promover o progresso econômico e social do país através de pesquisa e desenvolvimento - P\&D, e por meio dela delineou as diretrizes gerais para o fomento das pesquisas científicas e tecnológicas, bem como as bases legais para a interação entre as universidades e as empresas nesse ambiente, disciplinando as regras para proteção da produção intelectual no âmbito das ICT's (VETTORATO, 2008).

Assim, segundo Vettorato (2008), a Lei de Inovação Tecnológica brasileira, que tem origem em legislação francesa da mesma natureza, traça os nortes para incentivar a interação entre as universidades - ICT's e os setores de produção, a fim de fomentar o desenvolvimento científico e tecnológico no país, em consonância com a matriz constitucional anteriormente detalhada. Segundo sua análise, a comunidade científica e tecnológica do país se mobilizou e começou a debater a importância e a necessidade de uma legislação regulamentadora dos artigos 218 e 219 da Constituição Federal, o que culminou na edição da Lei de Inovação, cujo principal desafio seria corrigir um equívoco cultural brasileiro que atribuiu exclusivamente às universidades a responsabilidade pelo desenvolvimento científico e tecnológico do país, enquanto o setor produtivo apenas incorporava e usufruía do conhecimento produzido, quando em outros países tal desenvolvimento está atrelado às relações entre universidades, empresas e sociedade, por meio de ações de P\&D focadas nas necessidades e anseios de comunidades regionais. 
A Lei de Inovação, para cumprir tal desiderato, foi formulada com base em três eixos principais: estímulo à construção de ambientes especializados e cooperativos de inovação (art. $3^{\circ}$ ao art. $5^{\circ}$ ); estímulo à participação das ICT's no processo de inovação (art. 6ำ ao art. 18); estímulo à inovação nas empresas (art. 19 ao art. 21) (MATIAS-PEREIRA e KUGLIANSKAS, 2005; VETTORATO, 2008).

Segundo Veronese (2014), a Lei de Inovação tem como foco promover alterações que permitam formação de parcerias entre empresas privadas e instituições estatais e de órgãos específicos dedicados à inovação tecnológica, além da proteção e difusão de propriedade intelectual nas universidades e centros de pesquisa, destacando como mais relevante que a Lei não visa apenas flexibilizar a gestão de universidades e instituições de pesquisa, mas também permitir a formação de arranjos entre empresas inovadoras.

Machado e Rupphental (2014), por sua vez, destacam que a Lei de Inovação por si só não é suficiente para alcançar o desenvolvimento econômico e social, mas é importante destacar que ela constitui um marco, porque antes de sua vigência as ICT's possuíam visões díspares sobre inovação e metas baseadas exclusivamente na geração de conhecimento, num ambiente questionador da proximidade entre setor público e privado, a qual era vista negativamente ou até marginalizada pelos gestores e pesquisadores das ICT's.

Os pesquisadores (MACHADO E RUPPHENTAL, 2014), baseados em pesquisa bibliográfica e estudos sobre cada canal de transferência de tecnologia, apontam alguns pontos de conflito na aplicação prática da Lei de Inovação, entre eles: a) Divulgação de editais do processo de licenciamento e transferência de tecnologia - TT - com exclusividade - art. 6우 : pelo texto da Lei de Inovação é possível fazê-lo com ou sem exclusividade e as chamadas licenças não-exclusivas ocorrem normalmente, mediante de divulgação de tecnologias e busca de empresas potencialmente interessadas, sem necessidade da seleção da empresa por meio de publicação de edital, ou nos casos de relevante interesse público, em que somente podem ser efetuados a título não exclusivo. Já a licença com cláusula de exclusividade deve ser utilizada em obediência a procedimentos definidos em lei, com elaboração de edital que estabeleça em termos claros o objeto a ser licenciado, os critérios, as condições, a remuneração, os prazos de comercialização, a fim de garantir paridade entre os interessados e minimizar eventual contencioso para a ICT, tudo isso com a divulgação do mínimo possível de informações de forma que não seja revelada a essência ou novidade do objeto a ser licenciado, em razão da proteção da propriedade intelectual. Além disso, a necessidade de publicação na íntegra do edital no Diário Oficial da União é um dos conflitos, pois a Lei de Inovação e o respectivo Decreto № $5.563 / 2005$, que a regulamentou, determinam somente a "publicação do edital", não prevendo a suficiência da publicação de "avisos contendo os resumos dos editais", conforme estabelece a Lei n. 8.666/1993 (Lei de Licitações).

b) Acordos de parceria para pesquisa, desenvolvimento e inovação - art. 9: a propriedade intelectual e os direitos de uso dos possíveis resultados da parceria devem estar definidos em contrato, porque o resultado da parceria (patente, por exemplo) poderá ter co-titulares e ser explorado pelas partes ou só uma delas, devendo ser solucionada a questão da concessão de exclusividade para exploração dos resultados obtidos pela parceria, porque algumas ICT's consideram que se a escolha do parceiro observou princípios legais e constitucionais, o objeto da parceria deve ser considerado como tendo sido desenvolvido pelas partes, independentemente da definição contratual da titularidade e, assim, as ICT's têm buscado dar prioridade 
de uso para as empresas envolvidas na parceria, tangenciando o aspecto da exclusividade, mas sem conceder a exclusividade.

c) Incentivos financeiros aos pesquisadores decorrentes dos ganhos econômicos das ICT's resultantes de contratos de transferência de tecnologia e de licenciamento para outorga de direito de uso ou de exploração de criação protegida - art. 13: as pessoas envolvidas nas atividades de P\&D poderá se beneficiar da bolsa de estimulo à inovação, da remuneração pela prestação de serviços e dos ganhos oriundos de licenciamento e TT (royalties). Porém, a Lei de Inovação não diz ser obrigatório o pagamento de bolsa ao pesquisador, o que constitui apenas uma alternativa. Os autores destacam que a bolsa deve ser entendida como instrumento jurídico, não importando seu acúmulo pelo pesquisador. Outra questão é a dificuldade de operacionalização do recebimento e utilização dos ganhos econômicos, resultantes dos contratos de licenciamento e transferência de tecnologia, e outra, ainda, é a limitação de ganhos econômicos muito expressivos, uma vez que algumas ICT's têm estipulado limite máximo de $1 / 3$ dos royalties a serem recebidos pelo pesquisador. Não bastasse, ainda há o problema da tributação sobre tais valores recebidos pelos pesquisadores. Normas do Instituto Nacional do Seguro Social - INSS - preveem que importâncias referentes a bolsas de estudo não integram sua base de cálculo. Por sua vez, a Lei no 9.250/1985 prevê a isenção do Imposto de Renda sobre bolsas de estudo. Porém, tais legislações não mencionam especificamente a bolsa de inovação, de nova modalidade e regulamentada pela Lei de Inovação. As ICT's têm entendido que sobre as bolsas não incide qualquer encargo ou imposto, mas a Receita Federal entende que o pagamento de bolsa não pode configurar benefício econômico financeiro para a instituição que a paga e, embora possa-se afirmar que as Fundações de Apoio à Pesquisa que pagam as bolsas não têm interesse econômico e financeiro, por sua natureza sem finalidade lucrativa, os recursos são provenientes de um contrato ou convênio firmado com uma empresa privada, esta sim com interesses econômicofinanceiros na pesquisa e no desenvolvimento. A Lei de Inovação não oferece uma solução para tal problema.

d) Mobilidade do pesquisador - arts. 14 e 15: a Lei de Inovação faculta ao pesquisador afastar-se totalmente da ICT para constituir empresa, ou afastar-se parcialmente, mantendo no mínimo sua atividade de docente. $O$ problema surge quando 0 pesquisador é sócio de empresa, em que pode explorar um conhecimento da universidade, protegido ou não. Quando não é protegido, pode-se explorá-lo normalmente numa empresa incubada ou fora do ambiente acadêmico. Porém, quando é protegido, entende-se que não é permitida a exploração de uma patente por um funcionário da ICT que seja sócio ou que esteja trabalhando em empresa, sem a formalização da TT ou da exploração de criação protegida. Além disso, as áreas jurídicas de algumas ICT's têm entendido não ser permitida a exploração de uma criação protegida - da qual o pesquisador, como funcionário da ICT, é inventor - pela empresa por ele constituída ou da qual ele se tornou sócio, pois a ICT passaria a beneficiar uma empresa em particular, da qual o seu pesquisador é sócio, o que feriria o princípio da impessoalidade, um dos que norteiam a atuação da Administração Pública. A interpretação dos setores jurídicos é de que o licenciamento para a exploração da criação protegida deve ocorrer em igualdade de condições para qualquer candidato interessado, não apenas a uma empresa a que um pesquisador esteja vinculado. Contudo, o desconhecimento geral dos setores jurídicos sobre a dinâmica do processo de negociação e transferência de tecnologia prejudica a boa aplicação da Lei da Inovação. 
e) Obrigatoriedade de Núcleos de Inovação Tecnológica - NIT - em todas as ICT's art. 2: o NIT formalizou-se como interlocutor da ICT com as empresas e com a própria instituição no que diz respeito à propriedade intelectual e inovação, concedendo apoio ao pesquisador que muitas vezes assumia essa responsabilidade. Assim, há que se reconhecer a competência e importância do NIT. Contudo, não se sabe ao certo quais são as atribuições do NIT, sua capacidade e delegação de poder para auferir normas, avaliar tecnologias, controlar a divulgação de resultados, formalização de parcerias e solução de eventuais conflitos de interesse, entre outras questões, o que deve ser definido minuciosamente no ato de sua criação ou no regramento de sua atuação.

Machado e Rupphental (2014) concluem que é preciso tomar cuidado para que o tema da inovação e outros a ela relacionados - proteção do conhecimento, licenciamento e transferência de tecnologia, parceria público-privada - não sejam burocratizados, criando mais um entrave à viabilização das ações institucionais, razão pelo que os pontos que dificultariam a aplicação da Lei de Inovação deveriam ser sanados.

\subsection{A Lei do Bem}

A Lei de Incentivo à Inovação, ou Lei do Bem (Lei Federal no 11.196 , de 21 de novembro de 2005) estabeleceu incentivos fiscais instituídos em cumprimento ao art. 28 da Lei de Inovação Tecnológica, instituindo ainda o Regime Especial de Tributação para a Plataforma de Exportação de Serviços de Tecnologia da Informação (REPES), o Regime Especial de Aquisição de Bens de Capital para Empresas Exportadoras (RECAP) e o Programa de Inclusão Digital (CALIENDO e MUNIZ, 2014).

Segundo Caliendo e Muniz (2014), entre os incentivos reais previstos na Lei do Bem destinados à pesquisa, desenvolvimento e inovação nas empresas, destacamse:

a) Exclusão do lucro líquido e da base de cálculo da contribuição social sobre o lucro líquido (CSLL), do valor correspondente de até $60 \%$ da soma dos dispêndios, classificados como despesas operacionais pela legislação do Imposto de Renda de Pessoa Jurídica - IRPJ, realizados com pesquisa e desenvolvimento no ano base considerado.

b) Adição de até $20 \%$, no caso de incremento do número de pesquisadores dedicados exclusivamente à pesquisa e desenvolvimento contratados no ano de referência.

c) Adição de até $20 \%$, na soma dos dispêndios ou pagamentos vinculados à pesquisa tecnológica e desenvolvimento de inovação tecnológica objeto de patente concedida ou cultivar registrado.

d) Redução de $50 \%$ do imposto sobre produtos industrializados - e IPI na compra de máquinas, equipamentos, aparelhos e instrumentos (nacionais ou importados) destinados ao uso exclusivo de pesquisa tecnológica e desenvolvimento de inovação tecnológica.

e) Redução à zero da alíquota do imposto de renda incidente sobre as remessas ao exterior destinadas aos pagamentos de registro de manutenção de marcas, patentes e cultivares.

f) Depreciação acelerada integral, sem prejuízo da depreciação normal dos equipamentos, máquinas, aparelhos e instrumentos no próprio período de aquisição, destinados à pesquisa, desenvolvimento e inovação para fins de IRPJ e CSLL.

g) Dedução do saldo não depreciado dos equipamentos, máquinas, aparelhos e instrumentos destinados à pesquisa, desenvolvimento e inovação, no ano em que for concluída a sua utilização. 
h) Amortização acelerada (dedução) dos dispêndios relativos à aquisição de bens intangíveis destinados à pesquisa, desenvolvimento e inovação, no ano base.

i) Dedução do saldo não amortizado dos dispêndios relativos à aquisição de bens intangíveis destinados à pesquisa, desenvolvimento e inovação, no ano em que for concluída a sua utilização.

j) Exclusão, para efeito de apuração do IRPJ e da CSLL, de $50 \%$ a $250 \%$ dos dispêndios efetivados em projetos de pesquisa científica e tecnológica executada por instituição científica e tecnológica (ICT), cuja operacionalização é executada sob a gestão da Coordenação de Aperfeiçoamento de Pessoal de Nível Superior (CAPES).

Para Caliendo e Muniz (2014), mediante tais incentivos fiscais, a Lei do Bem apresenta-se na linha de frente da promoção da inovação, conferindo autonomia e possibilidades de incremento produtivo do mercado interno e constituindo um instrumento na afirmação da soberania nacional nos segmentos de pesquisa e desenvolvimento. Contudo, os mesmos autores afirmam que, a despeito disso, a efetividade dos incentivos fiscais legalmente previstos é ainda baixa e, para sustentar tal afirmação, utilizam dados divulgados pelo Ministério da Ciência, Tecnologia e Inovação por meio do Relatório Anual da Utilização de Incentivos Fiscais, o qual, em 2011, indicava que 972 empresas foram cadastradas como aderentes ao usufruto dos incentivos fiscais do Capítulo III da Lei do Bem, enquanto em 2013 esse número havia subido para 1.042 empresas, um incremento de 8\%. Num universo de 5,4 milhões de empresas formais, como já mencionado no item 3.3 acima, há que se concordar com os autores que, embora crescente, ainda é tímida a efetiva adesão do empresariado a essa política pública, não havendo, igualmente, dados sobre o número de patentes geradas, empregos, faturamento ou crescimento do market share (quota de mercado) dessas empresas.

Percebe-se, portanto, que apesar dos incentivos concedidos, como afirmado por Caliendo e Muniz (2014), a adesão de empresas brasileiras aos benefícios concedidos pela Lei do Bem ainda é tímida, em relação ao universo de empresas formais existentes.

\subsection{Código de Ciência, Tecnologia e Inovação}

Recentemente, foi aprovada a Lei Federal no 13.243, de 11 de janeiro de 2016, que instituiu o Código de Ciência, Tecnologia e Inovação, a qual promoveu significativa modificação do texto original da Lei de Inovação. Evidentemente, em razão da novidade de publicação do Código, não existem muitos estudos publicados a respeito.

Um estudo de Rauen (2016) constitui uma das primeiras tentativas que detalha minuciosamente as alterações promovidas na Lei de Inovação pelo Código De Ciência, Tecnologia e Inovação, especialmente no que diz respeito à interação de instituições de ciência e tecnologia e empresas privadas. Segundo a autora, o novo Código é resultado de um processo de cerca de cinco anos de discussões entre atores do Sistema Nacional de Inovação (SNI) nos âmbitos das Comissões de Ciência e Tecnologia da Câmara e do Senado, as quais tinham como ponto de partida o reconhecimento e a necessidade de alterar pontos na Lei de Inovação e em outras nove leis relacionadas ao tema, de modo a reduzir obstáculos legais e burocráticos e conferir maior flexibilidade às instituições atuantes nesse sistema.

Para Rauen (2016) o Código avança em diversos pontos na promoção de um ambiente regulatório mais seguro e estimulante para a inovação no Brasil, destacando-se: a formalização das ICT's privadas (entidades privadas sem fins 
lucrativos) como objeto da lei; a ampliação do papel dos NIT's, incluindo a possibilidade de que fundações de apoio possam ser NIT's de ICT's; a diminuição de alguns dos entraves para a importação de insumos para pesquisa e desenvolvimento (P\&D); a formalização das bolsas de estímulo à atividade inovativa, entre outros.

Especificamente no que diz respeito à interação entre ICT's e empresas, o Código propôs alterações com fim de reduzir significativamente pontos críticos de insegurança jurídica, dando mais clareza à aplicação e à operacionalização da lei, bem como fortalecendo as ferramentas de estímulo à participação de ICT's em atividades de inovação associadas ao segmento produtivo (RAUEN, 2016).

Para tanto, entre outras medidas, o Código de Ciência, Tecnologia e Inovação, em relação à redação original da Lei de Inovação, expandiu o conceito de ICT a outras entidades, como as instituições de direito privado sem fins lucrativos, abrangendo e oficializando importantes instituições que já fazem parte do SNI e que produzem pesquisa e geram inovações de grande impacto nacional, como as organizações sociais, criando a figura da ICT privada (RAUEN, 2016).

A Lei de Inovação original já previa a possibilidade das ICT's compartilharem laboratórios, equipamentos, instrumentos, materiais e demais instalações em atividades de incubação e a permissão para utilização dessas instalações para a realização de atividades de pesquisa, mediante remuneração para as ICT's engajadas nessas atividades (BRASIL, 2004). O Código ampliou a possibilidade de que a contrapartida para compartilhamento e permissão de utilização de instalações de ICT's públicas seja financeira ou não financeira, em vez de apenas "remunerada", como na redação original, possibilitando, assim, às ICT's poderem receber como forma de contrapartida de compartilhamento, por exemplo, o protótipo resultante do processo de incubação de empresas para o desenvolvimento tecnológico, prática comum que passa, agora, a ser oficializada (RAUEN, 2016).

No caso do recebimento de recursos financeiros de empresas, a insegurança jurídica que residia na redação original da Lei de Inovação era a de que a lei não definia de que forma esses recursos deveriam ser captados pelas ICT's, considerando que elas, como órgãos da administração pública, não possuem "caixas" próprios para o recebimento de recursos financeiros privados (extra orçamentários), o que o Código vem corrigir ao possibilitar às empresas privadas contratantes repassar os recursos diretamente às Fundações de Apoio, que funcionarão como "caixas" das ICT's, o que torna claro que os recursos advindos de atividades de inovação poderão permanecer na instituição (RAUEN, 2016).

Ainda de acordo com Rauen (2016), em relação ao art. 4ํ da Lei de Inovação, foram várias alterações. Primeiro, ao alterar a redação do inciso I, empregando a expressão "ICT ou empresas", a Lei de Inovação deixa de restringir a micro ou pequenas empresas o compartilhamento de instalações em atividades de incubação, ampliando a incubação para outras ICT's e empresas de qualquer porte econômico, oficializando a incubação de projetos tecnológicos, em que equipes de empresas ficam incubadas para desenvolver seus projetos tecnológicos em parceria com equipes de institutos de pesquisa. Quanto à alteração da redação do inciso II, do art. 4ํㅡㄹ incluindo os termos "ICT" e "pessoas físicas", o Código oficializa uma prática comum do acesso a instalações de ICT's por outras instituições ou pessoas físicas (pesquisadores e estudantes). Ao acrescentar o inciso III ao art. 4ํㅡㄹ da Lei de Inovação, o Código cria o conceito de "capital intelectual" entre os bens que podem ser acessados nas ICT's para o desenvolvimento de projetos de inovação e que consiste no conhecimento acumulado pelo pessoal da organização, oficializando, portanto, as atividades já prestadas por pesquisadores de ICT's em projetos de 
inovação. Rauen (2016) ressalva, porém, que nesse aspecto o Código cria nova insegurança jurídica, pois não disciplina como o acesso a esse capital intelectual deve ser disponibilizado, limitado ou remunerado. Outra ressalva diz respeito à nova redação do parágrafo único do art. 4ํㅜㄹ que não esclarece como a ICT pública deve assegurar igualdade de oportunidades de acesso a suas instalações.

Como já mencionado, o Código alterou a redação da Lei 8.958/1994, que trata das relações entre as instituições federais de ensino superior e de pesquisa científica e tecnológica e as fundações de apoio, explicitando as possibilidades e a operacionalização da captação dos recursos financeiros extra orçamentários advindos do compartilhamento e permissão para utilização de instalações de ICT's mediante fundações de apoio associadas a estas (RAUEN, 2016). Contudo, não houve alteração dos parágrafos $2^{\circ}, 3^{\circ}$ e $4^{\circ}$, do art. $8^{\circ}$, da Lei de Inovação, os quais tratam do recebimento de retribuição pecuniária por pesquisadores envolvidos nessas atividades, o que, segundo Rauen (2016), significou a perda de oportunidade de esclarecer e sistematizar como esses valores devem ser calculados, o tempo de dedicação do pesquisador a essas atividades e a forma de recebimento dessa retribuição, o que deve manter subutilizada essa forma de incentivo ao envolvimento de pesquisadores públicos na prestação de serviços em atividades inovativas.

Rauen (2016) destaca, como uma das principais alterações promovidas pelo Código de Ciência e Tecnologia à Lei de Inovação, o tratamento dado a acordos de parceria que oficializa uma prática usual entre as ICT's, referente à cessão de direitos de propriedade intelectual das criações resultantes da parceria ao parceiro privado.

Outra novidade trazida pelo Código e destacada por Rauen (2016) diz respeito à possibilidade do Núcleo de Inovação Tecnológica - NIT - adquirir personalidade jurídica própria, inclusive como fundação de apoio, conforme alteração promovida na Lei no 8.958/1994, o que dará a tais instituições maior flexibilidade na gestão de seus recursos financeiros (dissociados das ICT's), maior celeridade e possiblidade de atração de perfis e contratação de funcionários mais qualificados em relação às atribuições previstas e, consequentemente, maior profissionalismo na gestão da política de ciência, tecnologia e inovação das ICT's.

É importante mencionar que o Código de Ciência, Tecnologia e Inovação alterou, além das já mencionadas Lei de Inovação Tecnológica e Lei no 8.958/1994, outras sete leis, a saber: a) Lei no 6.815/1980, que define a situação jurídica do estrangeiro no Brasil; b) Lei no 8.666/1993, que institui normas para licitações e contratos da Administração Pública; c) Lei no 12.462/2012, que institui o Regime Diferenciado de Contratações Públicas (RDC); d) Lei no 8.745/1993, que dispõe sobre a contratação por tempo determinado para atender a necessidade temporária de excepcional interesse público; e) Lei no 8.010/1990, que dispõe sobre importações de bens destinados à pesquisa científica e tecnológica; f) Lei no 8.032/1990, que dispõe sobre a isenção ou redução de impostos de importação e; g) Lei № 12.772/2012, que trata da estruturação do Plano de Carreiras e Cargos de Magistério Federal (PEREIRA, 2015).

No que diz respeito à Lei no 6.815/1980, o Código tratou da concessão de visto temporário a estrangeiro que pretenda vir ao Brasil na condição de cientista, pesquisador, professor, técnico ou profissional de outra categoria, sob regime de contrato ou a serviço do governo brasileiro (inciso $\mathrm{V}$, do art. 13), ou na condição de beneficiário de bolsa vinculada a projeto de pesquisa, desenvolvimento e inovação concedida por órgão ou agência de fomento (inciso VIII, do art. 13) (BRASIL, 2016).

Quanto às leis de licitações (8.666/1993) e do Regime Diferenciado de Contratações Públicas - RDC (12.462/2012), o novo Código incluiu o conceito de 
produtos para pesquisa e desenvolvimento - bens, insumos, serviços e obras necessários para atividade de pesquisa científica e tecnológica, desenvolvimento de tecnologia ou inovação tecnológica, discriminados em projeto de pesquisa aprovado pela instituição contratante (novo inciso XX, do art. 6으, da Lei no 8.666/1993); estipulou a dispensa de licitação para aquisição ou contratação de produto para pesquisa e desenvolvimento, limitada, no caso de obras e serviços de engenharia, a $20 \%$ do limite de um milhão e quinhentos mil reais na modalidade tomada de preços (novo inciso XXI, do art. 24, da Lei no 8.666/1993); determinou a dispensa de documentação para a contratação de produto para pesquisa e desenvolvimento, desde que obedecidos os demais requisitos legais (novo $\S 7^{\circ}$, do art. 32, da Lei no 8.666/1993); e estendeu 0 Regime Diferenciado de Contratações Públicas, previsto na Lei no 12.462/2012, para licitações e contratos necessários à realização de ações em órgãos e entidades dedicados à ciência, à tecnologia e à inovação (novo inciso X, da Lei no 12.462/2012) (BRASIL, 2016).

Já a Lei no 8.745/1993 passou a considerar necessidade temporária de excepcional interesse público a admissão de pesquisador, de técnico com formação em área tecnológica de nível intermediário ou de tecnólogo, nacionais ou estrangeiros, para projeto de pesquisa com prazo determinado, em instituição destinada à pesquisa, ao desenvolvimento e à inovação (nova redação do inciso VIII, do art. 2ํㅡ, da Lei no 8.745/1993) (BRASIL, 2016).

As Leis no 8.010/1990 e 8.032/1990 passaram a estender a isenção tributária ou redução do imposto sobre importação de bens destinados à pesquisa científica e tecnológica também para as ICT's e empresas, na execução de projetos de pesquisa, desenvolvimento e inovação, cujos critérios e habilitação serão estabelecidos pelo poder público, além dos pesquisadores, cientistas e entidades sem fins lucrativos beneficiados anteriormente pela Lei de Inovação. Interessante observar que, na redação do Código de Ciência Tecnologia e Inovação, a expressão "Instituição Científica, Tecnológica e de Inovação" substituiu "entidades sem fins lucrativos", que haviam sido incluídas originalmente no benefício pela Lei de Inovação. Posteriormente, a Medida Provisória no 718, de 16 de março de 2016, que tratou de medidas tributárias referentes à realização dos Jogos Olímpicos no Brasil, veio corrigir o equívoco (BRASIL, 2016).

Por fim, a Lei no 12.772/2012 passou a permitir que o professor de instituição de ensino superior federal, ainda que em regime de dedicação exclusiva, desde que não exerça cargo em comissão ou de confiança, possa ocupar cargo de dirigente máximo de fundação de apoio à pesquisa vinculada a ICT, inclusive podendo ser remunerado pelo exercício do cargo, se não for estatutário e tenha vínculo empregatício com a instituição ou, se for estatutário, se sua remuneração bruta for inferior a $70 \%$ (setenta por cento) do limite estabelecido para a remuneração de servidores do Poder Executivo federal. Além disso, a Lei no 12.772/2012 também passou a permitir ao professor, no regime de dedicação exclusiva, receber bolsa de ensino, pesquisa, extensão ou estímulo à inovação paga por agência oficial de fomento, por fundação de apoio devidamente credenciada por instituição federal de ensino ou por organismo internacional amparado por ato, tratado ou convenção internacional, além de ter limitado as atividades de trabalho eventual prestado no âmbito de projetos institucionais de ensino, pesquisa e extensão e colaboração esporádica de natureza científica ou tecnológica em assuntos de especialidade do docente, inclusive em polos de inovação tecnológica, a 8 horas semanais (BRASIL, 2016). 
Basicamente, são essas as principais mudanças trazidas pelo novo Código de Ciência, Tecnologia e Inovação, o qual regulamentou a Emenda Constitucional 85 e promoveu alterações na Lei de Inovação Tecnológica e várias outras normas que tivessem relação com as atividades de ciência, tecnologia e inovação.

\section{CONSIDERAÇÕES FINAIS}

A partir das referências utilizadas no presente trabalho, tem-se que existe hoje, no Brasil, um subsistema normativo de Ciência, Tecnologia e Inovação, o qual é constituído a partir de normas previstas na Constituição Federal (arts. 218 e 219), as quais são regulamentadas e complementadas pela Lei de Inovação Tecnológica (2004), Lei do Bem (2005) e Código de Ciência, Tecnologia e Inovação (2016).

Esse subsistema normativo cria condições de existência para um ambiente favorável à produção de inovações tecnológicas e pesquisas na área de Ciência, Tecnologia e Inovação, estabelecendo incentivos às empresas para que invistam em pesquisa científica e regulando a aproximação e a formação de parcerias entre as universidades e as empresas.

A despeito disso, há carência de mais estudos a respeito da efetividade de tal subsistema normativo, ou seja, se de fato as leis cumprem seu objetivo de criar no país um ambiente favorável à produção de tecnologia de fronteira. 


\title{
Legal subsystem of Science, Technology and Innovation
}

\begin{abstract}
This paper aims to present an analysis of the legal subsystem of Science, Technology and Innovation in Brazilian law. Then, were used as references papers that deal with laws that regulate the activities of Science, Technology and Innovation, starting from the Federal Constitution and through the Innovation Law, Law of Good and the new Code of Science, Technology and Innovation. There was also an analysis of the mentioned texts of the laws, which constitute a real legal subsystem of Science, Technology and Innovation.
\end{abstract}

Key words: Science, Technology and Innovation; legal subsystem; law

\section{REFERÊNCIAS}

BRASIL. Lei no 13.243, de 11 de janeiro de 2016 - Código de Ciência, Tecnologia e Inovação. Diário Oficial [da] República Federativa do Brasil, Poder Executivo, Brasília, DF, 12 jan. 2016. Disponível em:

<http://www.planalto.gov.br/ccivil_03/_Ato2015-2018/2016/Lei/L13243.htm\#art2>. Acesso em: 29 abr. 2016.

BARBOSA, Denis Borges. Direito ao desenvolvimento, inovação e apropriação das tecnologias. Revista Jurídica da Casa Civil da Presidência da República, Brasília, v. 8, n. 83, p.31-50, fev./mar. 2007.

. Direito ao desenvolvimento, inovação e apropriação das tecnologias. Atualização do texto publicado na Revista Jurídica da Casa Civil da Presidência da República (Brasília, v. 8, n. 83, p.31-50, fev./mar. 2007) de acordo com a Emenda Constitucional 85. Rio de Janeiro, 2015. Disponível em:

<http://www.denisbarbosa.addr.com/arquivos/200/inovacao/direito_ao_desenvolvime nto_2015.pdf> Acesso em: 24 mar. 2016.

CALIENDO, Paulo; MUNIZ, Veyzon. Política fiscal e desenvolvimento tecnológicoempresarial: uma análise crítica sobre inovação e tributação. Revista de Direito Brasileira, ano 4, v. 8, p. 179-196, mai./ago.2014.

MACHADO, Filipe Molinar; RUPPHENTAL, Janis Elisa. Estudo dos pontos de conflito da Lei da Inovação. Int. J. Knowl. Eng. Manag., Florianópolis, v.3, n.6, p. 230-245, jul./nov., 2014.

MATIAS-PEREIRA, José; KRUGLIANSKAS, Isak. Gestão de inovação: a Lei de Inovação Tecnológica como ferramenta de apoio às políticas industrial e tecnológica do Brasil. RAE-Eletrônica, v. 4, n. 2, art. 18, jul./dez., 2005.

MENEZES, Robert Kalley Cavalcanti de. Considerações sobre a formação da política de ciência e tecnologia (PCT) brasileira para inovação. In: VIII Jornada 
Internacional de Políticas Públicas, São Luís, UFMA, 2015. Anais... 25 a 28 de agosto de 2015. 
PEREIRA, Reginaldo. O desenvolvimento sustentável no âmbito do marco legal de ciência e tecnologia no Brasil. RJurFA7, Fortaleza, v. 12, n. 2, p. 48-60, jul./dez. 2015.

RAUEN, Cristiane Vianna. O novo marco legal da inovação no Brasil: o que muda na relação ICT-empresa? Radar, IPEA, n. 43, fev.2016. Disponível em: <http://hdl.handle.net/11058/6048>. Acesso em: 1 mai. 2016.

VERONESE, Alexandre. A institucionalização constitucional e legal da ciência, tecnologia e inovação a partir do marco de 1988: os artigos 218 e 219 e a política científica e tecnológica brasileira. Revista Novos Estudos Jurídicos, Eletrônica, v. 19, n. 2, mai./ago. 2014

VETTORATO, Jardel Luís. Lei de Inovação Tecnológica: os aspectos legais da inovação no Brasil. Revista Eletrônica do Curso de Direito da UFSM, v. 3, n. 3, p. 60-76, set. 2008.

WILLIG, Júnior Roberto. Inovação tecnocientífica no Brasil: uma análise do contexto normativo e conceitual da inovação e a (in)definição dos seus limites éticos. 2014. 440 f. Dissertação (Mestrado em Direito). Universidade do Vale do Rio dos Sinos - UNISINOS, São Leopoldo, 2014. 